OPEN ACCESS

Edited by:

David Fuller,

University of Florida, USA

Reviewed by:

Vincent Joseph

Centre de recherche du $\mathrm{CHU}$ de

Québec, Canada

Irma Rukhadze,

David Geffen School of Medicine at

UCLA, USA

*Correspondence:

Fiona B. McDonald

fiona.mcdonald@bristol.ac.uk

Specialty section:

This article was submitted to

Respiratory Physiology,

a section of the journal

Frontiers in Physiology

Received: 16 December 2015

Accepted: 12 February 2016

Published: 04 March 2016

Citation:

McDonald FB, Dempsey EM and O'Halloran KD (2016) Early Life Exposure to Chronic Intermittent

Hypoxia Primes Increased

Susceptibility to Hypoxia-Induced Weakness in Rat Sternohyoid Muscle during Adulthood. Front. Physiol. 7:69.

doi: 10.3389/fphys.2016.00069

\section{Early Life Exposure to Chronic Intermittent Hypoxia Primes Increased Susceptibility to Hypoxia-Induced Weakness in Rat Sternohyoid Muscle during Adulthood}

Fiona B. McDonald ${ }^{1 *}$, Eugene M. Dempsey ${ }^{2}$ and Ken D. O'Halloran ${ }^{3}$

${ }^{1}$ Health Sciences Centre, School of Medicine and Medical Science, University College Dublin, Dublin, Ireland, ${ }^{2}$ Department of Paediatrics and Child Health, Cork University Maternity Hospital and the Irish Centre for Fetal and Neonatal Translational Research, University College Cork, Cork, Ireland, ${ }^{3}$ Department of Physiology, School of Medicine, University College Cork, Cork, Ireland

Intermittent hypoxia is a feature of apnea of prematurity (AOP), chronic lung disease, and sleep apnea. Despite the clinical relevance, the long-term effects of hypoxic exposure in early life on respiratory control are not well defined. We recently reported that exposure to chronic intermittent hypoxia $(\mathrm{CH})$ during postnatal development $(\mathrm{pClH})$ causes upper airway muscle weakness in both sexes, which persists for several weeks. We sought to examine if there are persistent sex-dependent effects of $\mathrm{pClH}$ on respiratory muscle function into adulthood and/or increased susceptibility to re-exposure to $\mathrm{ClH}$ in adulthood in animals previously exposed to $\mathrm{CH}$ during postnatal development. We hypothesized that $\mathrm{pClH}$ would cause long-lasting muscle impairment and increased susceptibility to subsequent hypoxia. Within $24 \mathrm{~h}$ of delivery, pups and their respective dams were exposed to $\mathrm{ClH}$ : $90 \mathrm{~s}$ of hypoxia reaching $5 \% \mathrm{O}_{2}$ at nadir; once every $5 \mathrm{~min}$, $8 \mathrm{~h}$ per day for 3 weeks. Sham groups were exposed to normoxia in parallel. Three groups were studied: sham; $\mathrm{pClH}$; and $\mathrm{pClH}$ combined with adult $\mathrm{ClH}(\mathrm{p}+\mathrm{aClH})$, where a subset of the $\mathrm{pClH}$-exposed pups were re-exposed to the same $\mathrm{ClH}$ paradigm beginning at 13 weeks. Following gas exposures, sternohyoid and diaphragm muscle isometric contractile and endurance properties were examined ex vivo. There was no apparent lasting effect of $\mathrm{pClH}$ on respiratory muscle function in adults. However, in both males and females, re-exposure to $\mathrm{CH}$ in adulthood in $\mathrm{pClH}$-exposed animals caused sternohyoid (but not diaphragm) weakness. Exposure to this paradigm of $\mathrm{ClH}$ in adulthood alone had no effect on muscle function. Persistent susceptibility in $\mathrm{pClH}$-exposed airway dilator muscle to subsequent hypoxic insult may have implications for the control of airway patency in adult humans exposed to intermittent hypoxic stress during early life.

Keywords: apnea, developmental plasticity, respiratory muscle dysfunction, upper airway patency, neonatal 


\section{INTRODUCTION}

The environment experienced during development can have long-lasting effects on structure and function of the respiratory system. Early life hypoxia is a common theme within the neonatal intensive care unit, primarily related to preterm infants. Altered oxygen availability during vulnerable periods of early life can ultimately induce persistent maladaptive outcomes in the respiratory control system (Bavis et al., 2004, 2010, 2011; Donnelly et al., 2005; Reeves et al., 2006; Prabhakar et al., 2007; Bavis and Mitchell, 2008; Mayer et al., 2013; Nanduri and Prabhakar, 2013). Perturbations in oxygen homeostasis during neonatal development can increase subsequent susceptibility to respiratory instability, thereby generating an underlying predisposition to the development of respiratory morbidity.

Intermittent hypoxia (IH) can be experienced during postnatal life in several different circumstances, notably apnea of prematurity (AOP), chronic lung diseases, and childhood obstructive sleep apnea (OSA) (Marshall and Wyche, 1972; Thach, 1985; Vuono et al., 2007; Katz, 2009; Pawar, 2012). McNamara and Sullivan (2000) have proposed that adult patients with sleep apnea may have been predisposed to developing apnea since early infancy. Indeed there is compelling evidence linking prematurity to increased risk of developing sleepdisordered breathing in childhood (Rosen et al., 2003; Hibbs et al., 2008; Raynes-Greenow et al., 2012), with one large-scale study revealing that diagnosis of sleep-disordered breathing is more prevalent in children born preterm, but not in those born small for gestational age (Raynes-Greenow et al., 2012). In broad terms, the long-term consequences of exposure to chronic $\mathrm{IH}$ during postnatal development $(\mathrm{pCIH})$ on adult respiratory system function are understudied. Although the underlying mechanisms giving rise to apneas apparent in AOP, childhood OSA and adult OSA may differ, if untreated they all result in various patterns of exposure to chronic intermittent hypoxia $(\mathrm{CIH})$, which has been shown in various animal models to be pivotal in the development, exacerbation, and perpetuation of various OSA-related co-morbidities, with resultant long-term adverse effects. Of relevance, exposure to $\mathrm{CIH}$ has been shown to alter the respiratory control system at multiple levels including aberrant remodeling in the peripheral sensors, medullary rhythm and pattern generators, and efferent motor pathways (Peng et al., 2003, 2004; Dick et al., 2007; Julien et al., 2008; Edge et al., 2012a).

Recently we reported that $\mathrm{pCIH}$ causes sternohyoid muscle impairment, which persists for at least 3 weeks upon return to a normoxic environment (McDonald et al., 2015b). Consistent with the notion of unique critical periods during development for respiratory-related maladaptive plasticity, we have demonstrated that the same $\mathrm{CIH}$ exposure does not significantly alter sternohyoid muscle force in adult rats (McDonald et al., 2014), notwithstanding that more frequent and/or intense exposures to $\mathrm{CIH}$ cause sternohyoid and diaphragm muscle dysfunction (McGuire et al., 2002; Pae et al., 2005; Shortt et al., 2014). The sternohyoid is one of several pharyngeal dilator muscles that play a pivotal role in the control of airway caliber. Phasic contraction of the sternohyoid-an infrahyoid muscle-during inspiration, in concert with suprahyoid muscles such as the geniohyoid, displaces the hyoid bone ventrally (anteriorly) and in this way the sternohyoid functions as a pharyngeal dilator muscle, complementing the actions of other major airway dilators such as the genioglossus (Roberts et al., 1984; Van De Graaff et al., 1984; Strohl et al., 1987; Van Lunteren et al., 1987a,b, 1989). The sternohyoid displays phasic inspiratory activity in the rat (O'Halloran et al., 2002) and is recruited during hypoxia and hypercapnia (O'Halloran et al., 2002), and during obstructive airway events (Edge et al., 2012b).

Pharyngeal dilator muscle dysfunction in humans increases the propensity for airway collapse, with relevance to AOP and OSA. Therefore, we posit that $\mathrm{pCIH}$-induced sternohyoid muscle weakness could serve to increase the risk of airway collapse in mammals, such as humans, with collapsible airways (particularly during sleep when airway tone decreases considerably). Thus, it is plausible to consider that early life exposure to $\mathrm{CIH}$ might result in persistent respiratory muscle dysfunction and/or increased susceptibility to subsequent stressors presenting later in life. The long-term consequences of $\mathrm{pCIH}$ on respiratory system function during adulthood are generally understudied, and there is a paucity of information concerning the effects of early life exposure to $\mathrm{CIH}$ on respiratory muscle function into adulthood, when many new challenges to respiratory homeostasis can often present, including alterations in the mechanics of the upper airway and neuromodulatory mechanisms controlling airway patency. We speculated that IH stress during postnatal development would cause persistent impairment in respiratory muscle function into adulthood. Moreover, we reasoned that animals exposed to $\mathrm{pCIH}$ stress would show increased susceptibility to $\mathrm{CIH}$ exposure presented again later in adult life.

\section{METHODS}

\section{Ethical Approval}

All protocols described in this study were performed under license from the Irish Government, Department of Health and Children in accordance with National and European legislation following institutional ethics committee approval.

\section{CIH Exposure}

A schematic of the study design is shown in Figure 1. Pregnant female Wistar rats were randomly divided into two groups: $\mathrm{pCIH}$ $(n=5)$ and sham $(n=3)$. Gas exposure of each dam and her respective litter began within $24 \mathrm{~h}$ of birth. The $\mathrm{CIH}$-exposed animals were housed conventionally in standard cages placed in environmental chambers (Oxycyler ${ }^{T M}$; Biospherix, NY, USA), wherein animals were exposed to $90 \mathrm{~s}$ of hypoxia $\left(5 \% \mathrm{O}_{2}\right.$ at the nadir) followed by $210 \mathrm{~s}$ of normoxia $\left(21 \% \mathrm{O}_{2}\right)$ i.e., 12 cycles per hour (see Figure 1). The hypoxia/re-oxygenation profile was run for eight consecutive hours during the light cycle. $\mathrm{CIH}$ exposure was performed daily for 3 weeks. The sham groups were exposed to a continuous normoxic environment in the same room. Animals had access to food and water ad libitum. Cages were routinely cleaned and food and water was replenished every second day. Animals were sexed from birth and body mass of the pups was monitored throughout the study (Figure 2). 

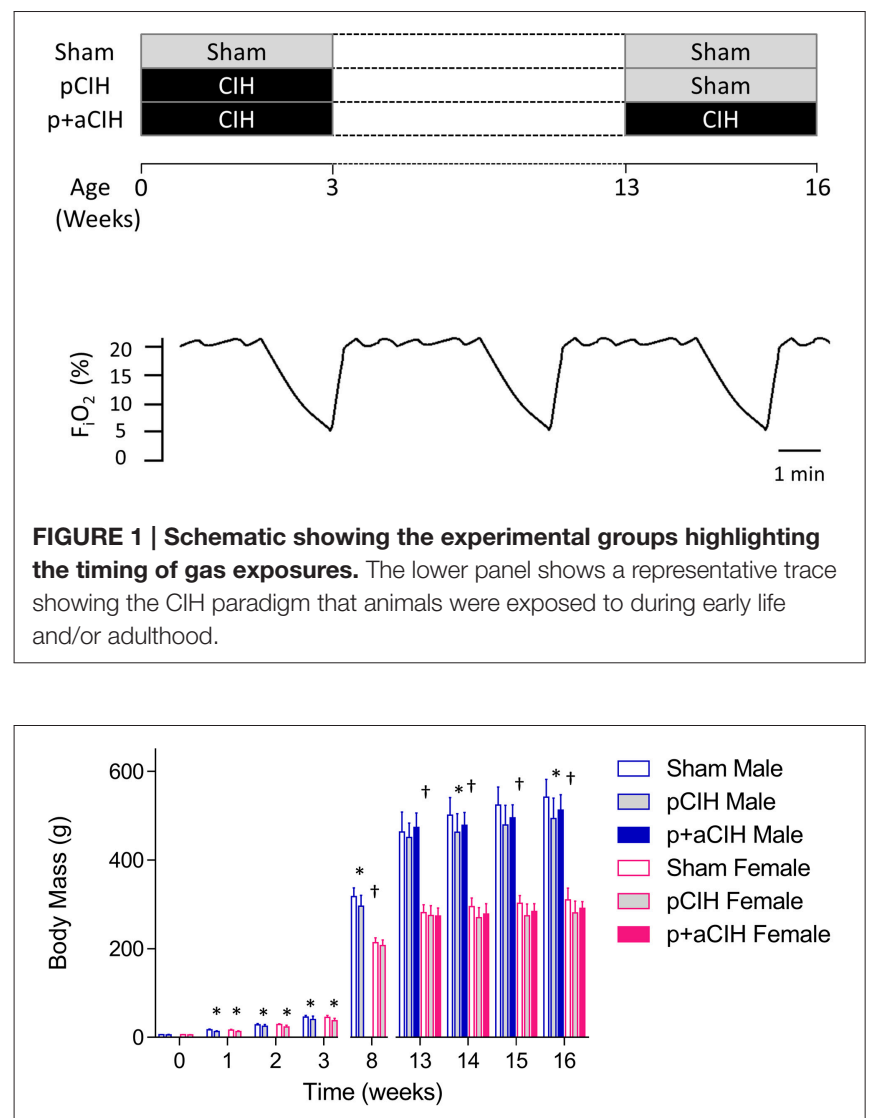

FIGURE 2 | Group data (mean \pm SD) for body mass in male and female animals in all groups. Data were analyzed by two-way (gas $\times$ sex) ANOVA. *Indicates significant difference from corresponding sham value $(p<0.05)$.

$\dagger$ Indicates significant difference from male values $(p<0.05)$; Sldak post-hoc test.

Following gas exposures, male $(n=27)$ and female $(n=25)$ pups were separated and assigned to one of three groups: sham, $\mathrm{pCIH}$, and $\mathrm{pCIH}+$ adult $\mathrm{CIH}(\mathrm{p}+\mathrm{aCIH})$. Thereafter, all groups remained in normoxia in the same general environment with routine care for 10 weeks. At week 13, the $\mathrm{p}+\mathrm{aCIH}$ group were re-exposed to $\mathrm{CIH}$ (same paradigm as described above) for a further 3 weeks. Sham and pCIH groups were exposed to normoxia in the same room during this period. All pCIH and $\mathrm{p}+\mathrm{aCIH}$ rats were studied the day after the completion of the adult $\mathrm{CIH}$ exposure period.

In separate trials, we examined the effects of $\mathrm{CIH}$ exposure (same paradigm as described above) on adult female sternohyoid and diaphragm muscle [sham $(n=8)$ vs. CIH $(n=8)$ ] to complement and extend our previous study in adult male rats demonstrating that the $\mathrm{CIH}$ paradigm described above has no effect on adult sternohyoid muscle function (McDonald et al., 2014).

\section{Experimental Protocol}

Rats were weighed, anesthetized with 5\% isoflurane and animals were killed by cervical dislocation. Sternohyoid muscles were excised and cut into at least two longitudinal strips. Diaphragm muscle was also excised and cut into strips including rib and central tendon. Tissue bundles were suspended vertically with fine (non-elastic) string; one end of each strip was mounted to tissue holders, while the other end was tied firmly to a hook, which was connected to an isometric force transducer. The muscle fiber bundles affixed to the tissue holders were then suspended in standard water-jacketed tissue baths. The tissue baths open to atmosphere were filled with Krebs salt solution, maintained at $35^{\circ} \mathrm{C}$ and bubbled with $95 \% \mathrm{O}_{2}$ and $5 \% \mathrm{CO}_{2}$ under control conditions (or with 95\% $\mathrm{N}_{2}$ and 5\% $\mathrm{CO}_{2}$ in separate studies to generate acute severe hypoxic stress). The Krebs solution contained: $120 \mathrm{mM} \mathrm{NaCl}, 25 \mathrm{mM} \mathrm{NaHCO}$, $12 \mathrm{mM} \mathrm{MgSO}_{4}, 1.2 \mathrm{mM} \mathrm{NaH}_{2} \mathrm{PO} 4,2.5 \mathrm{mM}$ CaGluconate, $5 \mathrm{mM}$ $\mathrm{KCl}$, and $11.5 \mathrm{mM}$ Glucose. D-tubocurarine $(25 \mu \mathrm{M})$ was used in all experiments to exclude any involvement of excitation of intramuscular nerve branches. The muscles were stimulated using supramaximal square wave constant current stimulators (S48 Stimulator, GRASS, Warwick, RI, USA), delivered via two platinum electrodes which flanked the tissue in the bath. The change in tension was transduced, amplified and converted from an analog-to-digital signal where it was displayed and recorded using Chart software (AD Instruments) on a computer for later analysis. Optimum muscle length $\left(\mathrm{L}_{\mathrm{o}}\right)$ was determined during repeated twitch stimulation while adjusting the length of the muscle with a micropositioner. The muscles were allowed to equilibrate for $10 \mathrm{~min}$ before starting the experimental protocol.

\section{Protocol}

Single twitch was evaluated by measuring the single twitch tension (Pt), contraction time (CT), and half-relaxation time (HRT). Force-frequency relationship was determined by sequentially stimulating the muscle at $10,20,30,40,60,80$, and $100 \mathrm{~Hz}$ (300 ms train duration) allowing a $1 \mathrm{~min}$ interval between stimulation. Peak tetanic force was determined at $100 \mathrm{~Hz}$ stimulation. Ten minutes following the force-frequency protocol, fatigue was assessed in response to repeated tetanic contractions $(40 \mathrm{~Hz}, 300 \mathrm{~ms}$ train duration) every $2 \mathrm{~s}$ for $5 \mathrm{~min}$. This is a well-established protocol for the study of respiratory muscle (Cantillon and Bradford, 1998, 2000; O'Halloran, 2006; McMorrow et al., 2011; Skelly et al., 2011, 2012; McDonald et al., 2015a,b). At the end of the experiment, the $\mathrm{L}_{\mathrm{o}}$ and weight of each muscle blotted dry was recorded in order to calculate cross-sectional area. The cross-sectional area of each strip was estimated by dividing the muscle mass (weight in grams) by the product of muscle $\mathrm{L}_{\mathrm{O}}$ (in $\mathrm{cm}$ ) and muscle density (assumed to be $\left.1.06 \mathrm{~g} / \mathrm{cm}^{3}\right)$.

\section{Data Analysis}

For isolated muscle studies, single twitch and peak tetanic force (determined at $100 \mathrm{~Hz}$ stimulation) was calculated in $\mathrm{N} / \mathrm{cm}^{2}$ of muscle cross-sectional area (CSA). Force-frequency relationship was determined by expressing force at each stimulus frequency as a $\%$ of peak force developed during the trial. Slope and $\mathrm{EF}_{50}$ values (i.e., stimulus frequency producing $50 \%$ of peak force) for sternohyoid and diaphragm muscle in sham and $\mathrm{CIH}$-exposed muscles were determined. Fatigue was determined during the repeated muscle stimulation trials as amplitude of final 
contraction / amplitude of initial contraction $\times 100$ i.e., $\%$ of control (initial) force. Data were compared statistically by two factor (gas $\times$ sex) analysis of variance (ANOVA). Two factor (gas $\times$ frequency) ANOVA was used for statistical judgment of force-frequency relationships; where appropriate, Sidak post-hoc tests were performed with $P<0.05$ chosen as the criterion for significance in all tests. All data are presented as mean \pm SD. Statistical tests were performed using GraphPad Prism 6 (Graph Pad Software, CA, USA).

\section{RESULTS}

\section{Body Mass, Hematocrit, and Cardiac Mass}

Data are shown in Table 1 and Figure 2. Exposure to pCIH decreased body mass at age 16 weeks in male rats compared with corresponding sham controls. There was no effect of exposure to $\mathrm{CIH}$ on hematocrit, right, and left cardiac ventricle mass (Table 1).

\section{Single Twitch Force and Contractile Kinetics}

Sternohyoid and diaphragm muscle single twitch force $(\mathrm{Pt})$ and contractile kinetics for sham, pCIH-, and $\mathrm{p}+\mathrm{aCIH}$-exposed male and female rats are shown in Figure 3 and Table 2. Pt was not significantly different between the three gas exposure groups in both male and female sternohyoid and diaphragm muscle. Similarly, contraction time and half-relaxation time were not significantly different between groups for both muscles in both sexes (Table 2).

\section{Peak Tetanic Force}

Representative traces are shown in Figure 3. Two way ANOVA (gas $\times$ sex) of sternohyoid muscle data sets revealed a significant gas effect $(P=0.004)$, with no significant independent sex effect and no interaction. Post-hoc analysis revealed a significant effect of $\mathrm{p}+\mathrm{aCIH}$ exposure compared with sham both in male and female sternohyoid muscle (Figure 4). pCIH exposure did not significantly affect sternohyoid muscle force at age 16 weeks in both sexes. This reveals the principal finding of the study: pCIH exposure does not affect adult rat sternohyoid muscle force per se; however, a subsequent exposure to $\mathrm{CIH}$ in pCIH-exposed animals, results in a significant reduction in peak force-generating capacity compared with sham control, and this effect is of equal measure in both sexes.

Diaphragm peak tetanic force data are presented in Figure 4. In contrast to sternohyoid, diaphragm peak force was not significantly different across the groups.

\section{Force-Frequency Relationship}

Force-frequency relationships for sternohyoid (Figure 5) and diaphragm (Figure 6) muscles in all groups are shown. There was a significant rightward shift in the male sternohyoid force-frequency relationship (Figure 5). Conversely, there was a significant leftward shift in the male diaphragm force-frequency relationship (Figure 6). Data for Hillslope and $\mathrm{EF}_{50}$ between the three groups in both males and females are also presented.

\section{Fatigue}

Representative traces are shown in Figure 3. CIH exposure did not affect sternohyoid or diaphragm muscle endurance in male or female rats (Figure 7).

\section{Hypoxic Tolerance}

Sternohyoid and diaphragm muscle function was also assessed ex vivo in tissue baths gassed with $95 \% \mathrm{~N}_{2} / 5 \% \mathrm{CO}_{2}$ to generate severe tissue hypoxia, which produced a loss of muscle strength compared with control preparations. However, there were no significant differences in contractile (Figure 8 and Table 3 ) and endurance (Figure 9) parameters comparing sham, pCIH, and $\mathrm{p}+\mathrm{aCIH}$ muscles under conditions of severe hypoxia.

\section{Effects of CIH Exposure during Adulthood on Sternohyoid and Diaphragm Muscle Function}

Exposure to $\mathrm{CIH}$ during adult life had no significant effect on contractile and endurance properties of the sternohyoid and diaphragm muscle of female rats (data not shown), consistent with our previous observation in male rats (McDonald et al., 2015b).

\section{DISCUSSION}

Despite the clinical relevance, the long-term effects of antecedent early life hypoxia on respiratory control are not well understood.

TABLE 1 | Group data for body mass (BM); hematocrit (HCT); right ventricular mass (RV); left ventricular mass (LV); and right ventricular mass: left ventricular mass ratio (RV/LV) (all expressed as mean \pm SD) in sham and ClH-exposed male and female rats.

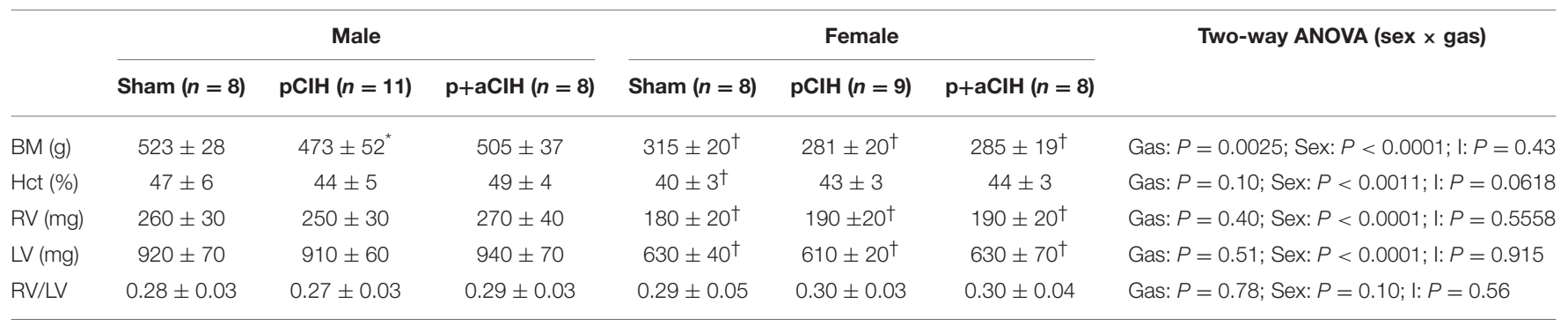

Data were analyzed by two-way (gas $\times$ sex) ANOVA. *Indicates significant difference from corresponding sham value; Sidak post-hoc test $(p<0.05)$. ${ }^{\dagger}$ Indicates significant difference from corresponding male value; Sidak post-hoc test $(p<0.05)$. 


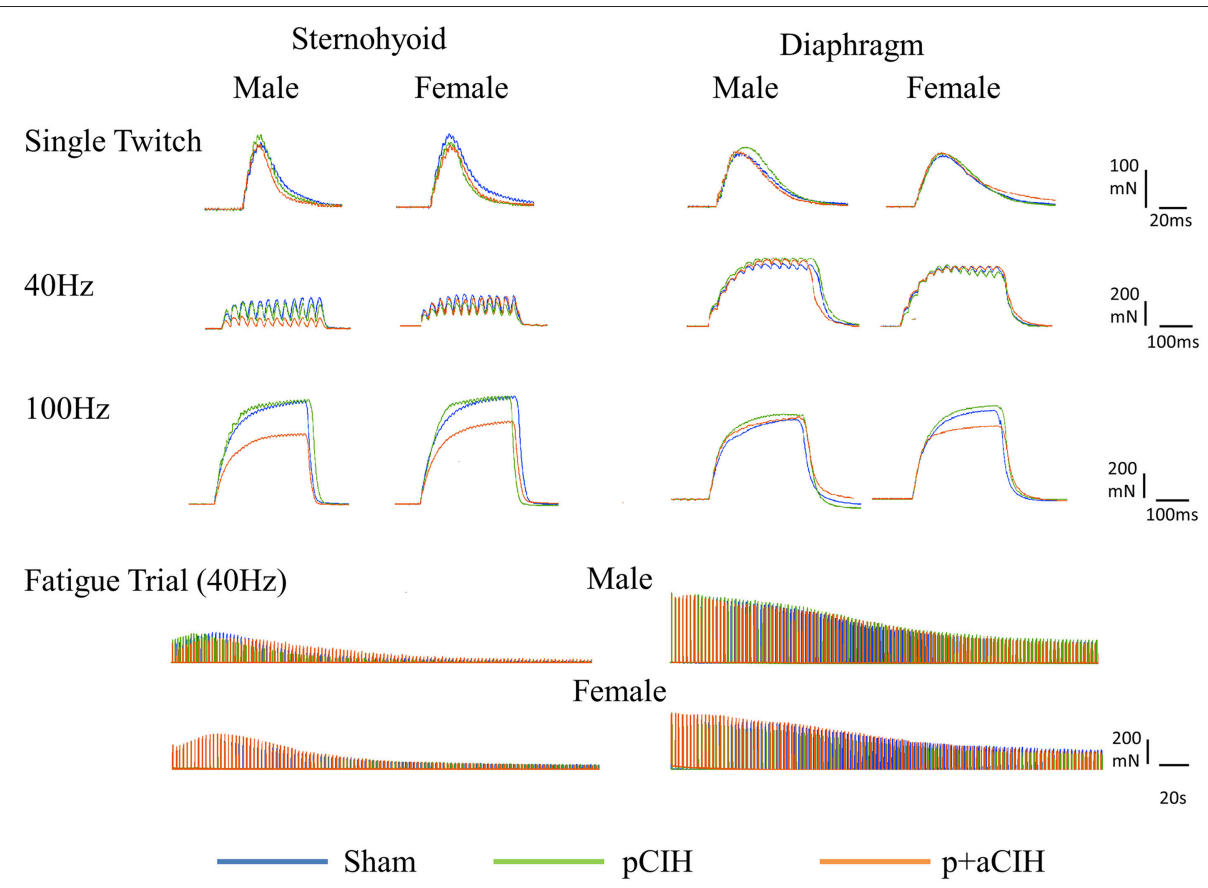

FIGURE 3 | Original representative traces from male and female sternohyoid (left panels) and diaphragm (right panels) muscle preparations from each experimental group: sham (blue), $\mathbf{p C I H}$ (green), and p+aCIH (red). Traces are superimposed to illustrate representative group effects. Peak tetanic force is achieved during $100 \mathrm{~Hz}$ stimulation. Note the relative depression of force in $\mathrm{p}+\mathrm{aClH}$ sternohyoid (but not diaphragm) compared with sham control.

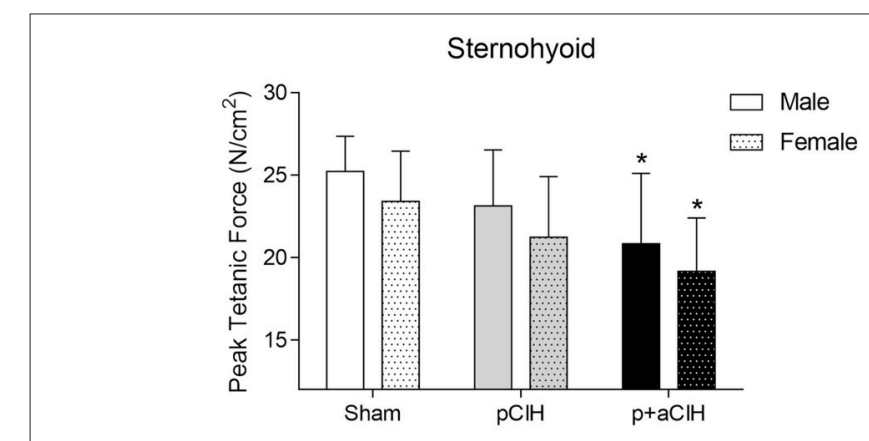

Gas: $\mathrm{P}=0.004$; Sex: $\mathrm{P}=0.08$; Interaction: $\mathrm{P}=0.996$

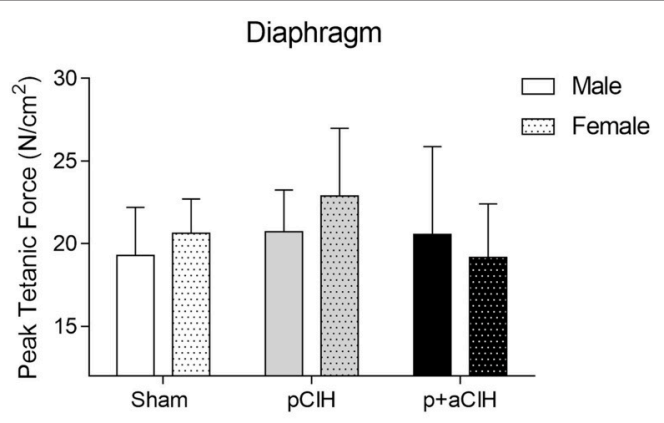

Gas: $P=0.19 ;$ Sex: $P=0.49 ;$ Interaction: $P=0.32$

FIGURE 4 | Group data (mean \pm SD) for sternohyoid and diaphragm muscle peak tetanic force in sham and CIH-exposed rats examined under control conditions ex vivo. Data were analyzed by two-way (gas $\times$ sex) ANOVA. " Indicates significant difference from corresponding sham ( $p<0.05$ ); Sidak post-hoc test.

This study was undertaken to investigate if there are persistent effects of pCIH exposure on respiratory muscle into adulthood. The data reveal that $\mathrm{pCIH}$-induced sternohyoid muscle impairment described previously by our group (McDonald et al., 2015 b) is apparently fully "recovered" by adulthood, insofar as when examined at 16 weeks, sternohyoid (and diaphragm) muscle is apparently not functionally different from age-matched sham exposed animals. However, of interest, pCIH-exposed sternohyoid muscle (but not diaphragm) retains an inherent susceptibility to subsequent hypoxic insult, such that when pCIH pre-conditioned muscle is re-exposed to $\mathrm{CIH}$ in adulthood (which itself has no effect on adult muscle (McDonald et al., 2014; this study), sternohyoid muscle weakness is revealed.
Studies that have examined the long-term ventilatory effects of postnatal intermittent hypoxia in rodents have shown persistent increases in normoxic ventilation and basal phrenic burst frequency, but blunted phrenic long-term facilitation (a form of respiratory neuroplasticity)and hypoxic ventilatory responses (Moss and Laferrière, 2006; Reeves et al., 2006). There is also evidence of long-lasting alterations induced by postnatal hypoxia on baroreflex function (Soukhova-O'hare et al., 2006). The present study is the first to examine the long-term effects of $\mathrm{pCIH}$ exposure on respiratory muscle function. Early life adversity can reportedly affect muscle function and metabolism. Some studies suggest that individuals born small for gestational age have reduced muscle mass (Phillips, 1995; Hediger et al., 1998; 
TABLE 2 | Group data (mean \pm SD) for peak twitch force (Pt), contraction time (CT), half-relaxation time (HRT), optimal length (Lo), and bundle cross-sectional area (CSA) of sham and $\mathrm{ClH}$-exposed male and female sternohyoid and diaphragm muscle preparations examined under control conditions ex vivo.

\begin{tabular}{|c|c|c|c|c|c|c|c|}
\hline & \multicolumn{3}{|c|}{ Male } & \multicolumn{3}{|c|}{ Female } & Two-way ANOVA (sex x gas) \\
\hline $\mathrm{Pt}\left(\mathrm{N} / \mathrm{cm}^{2}\right)$ & $5.3 \pm 1.1$ & $4.8 \pm 1.0$ & $4.4 \pm 0.6$ & $4.6 \pm 0.7$ & $4.0 \pm 0.9$ & $4.5 \pm 0.7$ & Gas: $P=0.12 ;$ Sex: $P<0.08 ; 1: P=0.25$ \\
\hline $\mathrm{CT}(\mathrm{ms})$ & $14 \pm 1$ & $14 \pm 1$ & $13 \pm 1$ & $14 \pm 1$ & $14 \pm 2$ & $14 \pm 1$ & Gas: $P=0.26$; Sex: $P=0.23 ;$ I: $P=0.062$ \\
\hline $\mathrm{HRT}(\mathrm{ms})$ & $12 \pm 2$ & $14 \pm 4$ & $10 \pm 3$ & $12 \pm 2$ & $13 \pm 1$ & $13 \pm 3$ & Gas: $P=0.39 ;$ Sex: $P=0.29 ;$ I: $P=0.25$ \\
\hline & Sham $(n=8)$ & $\mathrm{pCIH}(n=11)$ & $\mathrm{p}+\mathrm{aClH}(n=7)$ & Sham $(n=7)$ & $\mathrm{pClH}(n=9)$ & $\mathrm{p}+\mathrm{aClH}(n=7)$ & \\
\hline \multicolumn{8}{|c|}{ DIAPHRAGM } \\
\hline $\mathrm{Pt}\left(\mathrm{N} / \mathrm{cm}^{2}\right)$ & $4.3 \pm 1.1$ & $5.0 \pm 0.8$ & $4.9 \pm 0.9$ & $4.7 \pm 0.6$ & $5.6 \pm 1.4$ & $4.9 \pm 1.3$ & Gas: $P=0.07 ;$ Sex: $P=0.32 ; 1: P=0.78$ \\
\hline
\end{tabular}

Sham $(n=8) \quad \operatorname{pCIH}(n=11) \quad \mathrm{p}+\mathrm{aClH}(n=7) \quad \operatorname{Sham}(n=7) \quad \operatorname{pClH}(n=9) \quad \mathrm{p}+\mathrm{aClH}(n=7)$

Data were analyzed by two-way (gas $\times$ sex) ANOVA. ${ }^{\dagger}$ Indicates significant difference from corresponding male value; Sidak post-hoc test ( $\left.p<0.05\right)$.

\section{Sternohyoid}

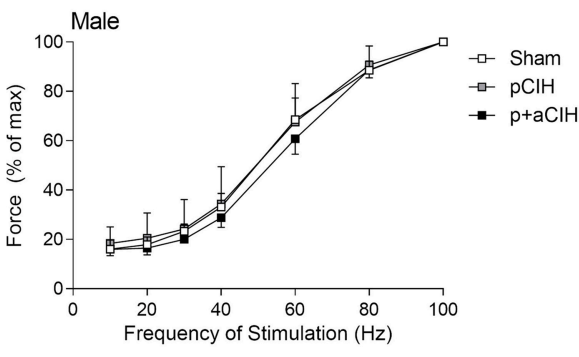

Gas $\mathrm{P}=0.03$; Frequency $\mathrm{P}<0.0001 ;$ Interaction $\mathrm{P}=0.97$

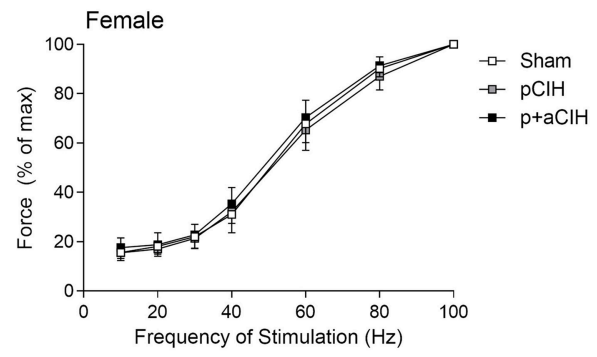

Gas $\mathrm{P}=0.02$; Frequency $\mathrm{P}<0.0001$; Interaction $\mathrm{P}=0.96$

\begin{tabular}{cccccccc}
\hline \multicolumn{7}{c}{ Male } & \multicolumn{5}{c}{ Female } \\
\hline & Sham & $\mathrm{pClH}$ & $\mathrm{p}+\mathrm{aClH}$ & Sham & $\mathrm{pClH}$ & $\mathrm{p}+\mathrm{aClH}$ & Two-way ANOVA \\
\hline $\mathrm{EF}_{50}$ & $57.7 \pm 7.3$ & $57.4 \pm 9.5$ & $60.6 \pm 3.6$ & $57.0 \pm 5.0$ & $59.7 \pm 8.5$ & $54.7 \pm 3.7$ & $\begin{array}{c}\text { Gas: } \mathrm{P}=0.89 \text {; Sex: } \mathrm{P}=0.14 ; \\
\text { Interaction } \mathrm{P}=0.47\end{array}$ \\
Slope & $4.3 \pm 0.9$ & $4.9 \pm 1.6$ & $4.8 \pm 1.0$ & $4.7 \pm 0.6$ & $4.2 \pm 1.0$ & $4.6 \pm 0.6$ & $\begin{array}{c}\text { Gas: } \mathrm{P}=0.81 ; \text { Sex: } \mathrm{P}=0.85 ; \\
\text { Interaction: } \mathrm{P}=0.63\end{array}$ \\
\hline
\end{tabular}

FIGURE 5 | Group data (mean \pm SD) for force-frequency relationship of sternohyoid muscle in male and female sham and CIH-exposed rats examined under control conditions ex vivo. Data were analyzed by two-way (gas $\times$ frequency) ANOVA in male and female data sets. Table: Group data (mean \pm SD) for EF 50 and Hillslope of sternohyoid in male and female sham and $\mathrm{ClH}$-exposed rats examined under control conditions ex vivo. Data were analyzed by two-way (gas $\times$ sex) ANOVA.

Gale et al., 2001; Sayer et al., 2004; Yliharsila et al., 2007) and impaired muscle strength in later life (Sayer et al., 1998, 2004; Kuh et al., 2002, 2006), which consequently increases disability and frailty. Furthermore, Jensen et al. (2007) showed, in a small cohort, that low birth weight altered subsequent skeletal muscle fiber composition and size.

We examined respiratory muscle responses to acute severe hypoxic challenge following $\mathrm{CIH}$ exposure in our model and observed no effect of $\mathrm{CIH}$ preconditioning on the depressant effects of acute severe hypoxia on sternohyoid and diaphragm muscle contractile and endurance properties. In recent years there is growing support for the "origin of adult disease in early life" hypothesis (De Boo and Harding, 2006). If adversity coincides with enhanced susceptibility during critical "windows" of development, it may alter the developmentally programmed phenotype, with potentially long-lasting deleterious 


\section{Diaphragm}

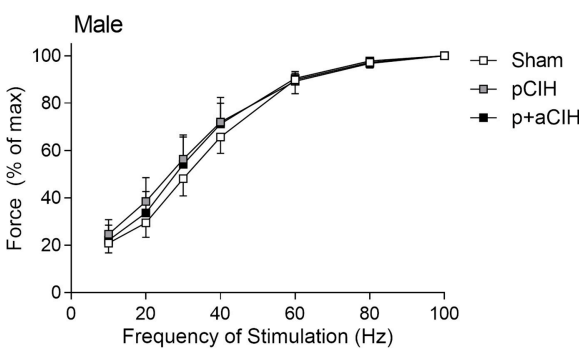

Gas $P=0.006$; Frequency $P<0.0001$; Interaction $P=0.44$

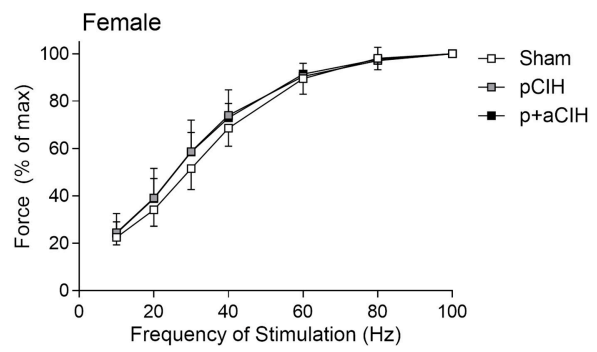

Gas $\mathrm{P}=0.08$; Frequency $\mathrm{P}<0.0001$; Interaction $\mathrm{P}=0.95$

\begin{tabular}{cccccccc}
\hline \multicolumn{7}{c}{ Male } & \multicolumn{7}{c}{ Female } \\
\hline & Sham & $\mathrm{pClH}$ & $\mathrm{p}+\mathrm{aClH}$ & Sham & $\mathrm{pClH}$ & $\mathrm{p}+\mathrm{aClH}$ & Two-way ANOVA \\
\hline $\mathrm{EF}_{50}$ & $37.5 \pm 3.4$ & $34.2 \pm 5.5$ & $33.8 \pm 5.0$ & $36.6 \pm 5.5$ & $31.2 \pm 7.6$ & $32.1 \pm 4.2$ & $\begin{array}{c}\text { Gas: } \mathrm{P}=0.049 ; \text { Sex: } \mathrm{P}=0.23 ; \\
\text { Interaction: } \mathrm{P}=0.85\end{array}$ \\
Slope & $3.3 \pm 0.8$ & $2.7 \pm 0.7$ & $2.7 \pm 0.4$ & $3.0 \pm 0.8$ & $2.8 \pm 0.4$ & $2.7 \pm 0.4$ & $\begin{array}{c}\text { Gas: } \mathrm{P}=0.19 ; \text { Sex: } \mathrm{P}=0.21 ; \\
\text { Interaction: } \mathrm{P}=0.39\end{array}$ \\
\hline
\end{tabular}

FIGURE 6 | Group data (mean \pm SD) for force-frequency relationship of diaphragm muscle in male and female sham, pCIH-, and p+aCIH-exposed rats examined under control conditions ex vivo. Data were analyzed by two-way (gas $\times$ frequency) ANOVA in male and female data sets. Table: Group data (mean \pm $\mathrm{SD}$ ) for $\mathrm{EF}_{50}$ and Hillslope of diaphragm in male and female sham, and $\mathrm{ClH}$-exposed rats examined under control conditions ex vivo. Data were analyzed by two-way (gas $\times$ sex) ANOVA.

Sternohyoid Fatigue Index

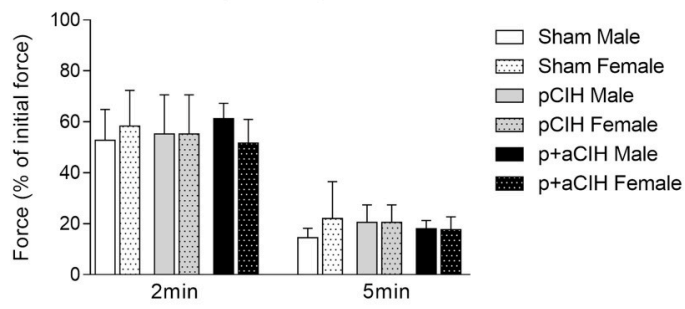

2min: Gas: $P=0.91$; Sex: $P=0.89$; Interaction: $P=0.31$ 5 min: Gas: $P=0.82$; Sex: $P=0.25$; Interaction: $P=0.42$
Diaphragm Fatigue Index

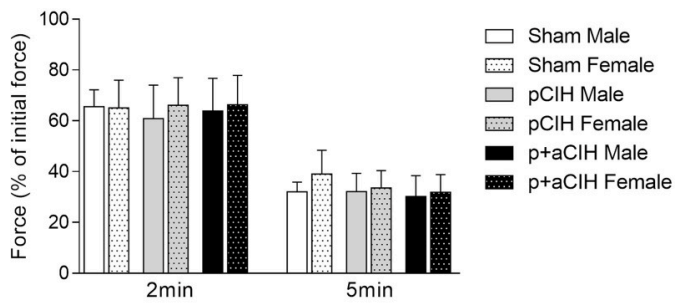

2min: Gas: $P=0.88$; Sex: $P=0.47$; Interaction: $P=0.76$ 5min: Gas: $P=0.23$; Sex: $P=0.10$; Interaction: $P=0.47$

FIGURE 7 | Group data (mean \pm SD) for fatigue index following 2 and $5 \mathrm{~min}$ of repeated muscle stimulation at $40 \mathrm{~Hz}$ in male and female sternohyoid and diaphragm muscle in sham and $\mathrm{CIH}$-exposed rats examined under control conditions ex vivo. Data for force are expressed as a \% of the initial (first) $40 \mathrm{~Hz}$ contraction during the fatigue trial. Data were analyzed by two-way (gas $\times$ sex) ANOVA.

consequences. The present study extends our previous work (McDonald et al., 2015b), which demonstrated that pCIH exposure results in sternohyoid muscle weakness in male and female rats, to illustrate that the airway dilator muscle appears to recover function with advancing age into adulthood. Our data show very little difference in sternohyoid (and diaphragm) muscle force and endurance at 16 weeks comparing sham and pCIH-exposed groups (both male and female rats). This is encouraging in some respects if the data here resemble potential outcomes of pCIH exposure in human infants. On the face of it, our data suggest that $\mathrm{pCIH}$-induced muscle dysfunction is restricted to a developmental timeline spanning the early life to adolescent period (McDonald et al., 2015b), and this disability appears to wane with advancing age (this study), once normal oxygen homeostasis is returned.
Our study revealed that early life exposure to $\mathrm{CIH}$ increased the susceptibility of sternohyoid muscles to subsequent hypoxic exposure later in life. It is interesting to consider that no material sex differences were observed in our study. Exposure to $\mathrm{p}+\mathrm{aCIH}$ decreased sternohyoid muscle force both in males and females, and the magnitude of the effect was similar in both sexes. The finding is consistent with our previous observation that $\mathrm{pCIH}$ exposure impairs male and female sternohyoid muscle force into adolescence ( $\mathrm{McD}$ onald et al., 2015b). It is suggested that human males may be more vulnerable to adversity than their female counterparts; for example, newborn males are more at risk of developing respiratory disorders (including SIDS) than females (Mage and Donner, 2006). Our studies (McDonald et al., 2015b; this study) clearly illustrate, however, that early life exposure to $\mathrm{CIH}$ 


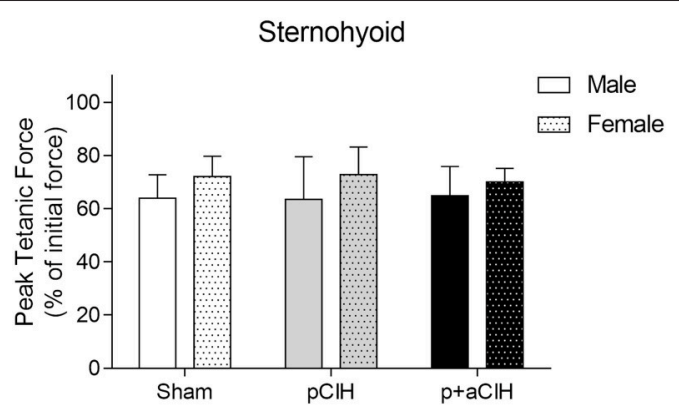

Gas: $\mathrm{P}=0.98$; Sex: $\mathrm{P}=0.02$; Interaction: $\mathrm{P}=0.86$

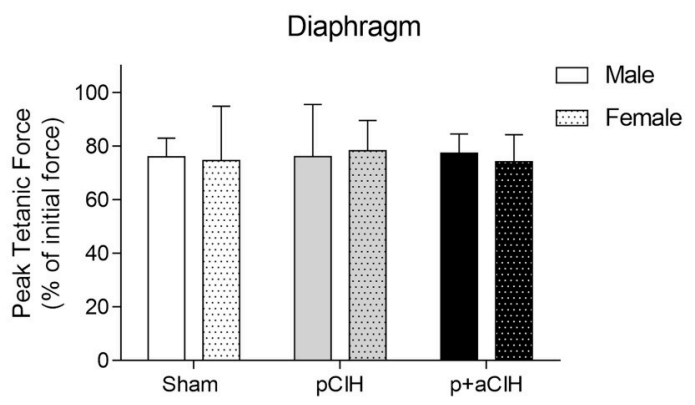

Gas: $\mathrm{P}=0.92$; Sex: $\mathrm{P}=0.84$; Interaction: $\mathrm{P}=0.85$

FIGURE 8 | Group data (mean \pm SD) for sternohyoid and diaphragm muscle peak tetanic force in sham and CIH-exposed rats examined during acute severe hypoxic stress ex vivo. Data for force during hypoxia are expressed as a \% of baseline (control) force determined in hyperoxia to illustrate the depressant effect of severe hypoxia on peak tetanic force at $100 \mathrm{~Hz}$. Data were analyzed by two-way (gas $\times$ sex) ANOVA.

Sternohyoid Fatigue Index

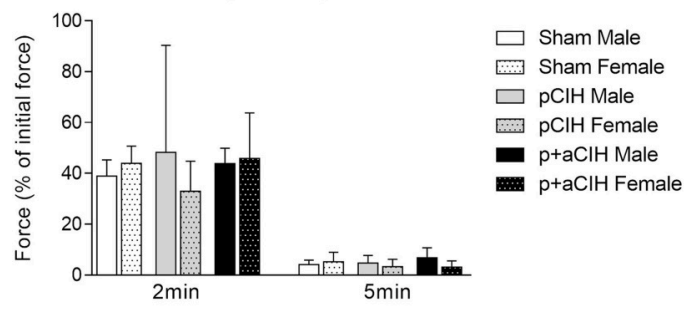

2min: Gas: $P=0.84$; Sex: $P=0.65$; Interaction: $P=0.35$ 5min: Gas: $P=0.66$; Sex: $P=0.14$; Interaction: $P=0.11$
Diaphragm Fatigue Index

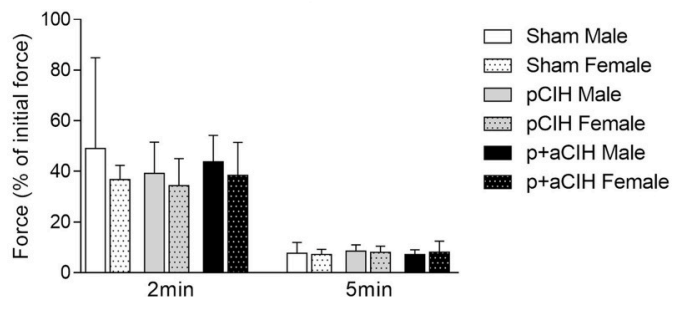

2min: Gas: $P=0.62$; Sex: $P=0.17$; Interaction: $P=0.83$ $5 \mathrm{~min}$ : Gas: $\mathrm{P}=0.73$; Sex: $\mathrm{P}=0.98$; Interaction: $\mathrm{P}=0.77$

FIGURE 9 | Group data (mean \pm SD) for fatigue index following 2 and 5 min of repeated muscle stimulation at $40 \mathrm{~Hz}$ in male and female sternohyoid and diaphragm muscle in sham and $\mathbf{C I H}$-exposed rats examined during acute severe hypoxic stress ex vivo. Data for force are expressed as a \% of the initial (first) $40 \mathrm{~Hz}$ contraction during the fatigue trial. Data were analyzed by two-way (gas $\times$ sex) ANOVA.

adversely affects male and female rat respiratory muscle in equal measure.

We observed differential effects comparing sternohyoid and diaphragm muscle responses to combined $\mathrm{CIH}$ exposure $(\mathrm{p}+\mathrm{aCIH})$. Sternohyoid and diaphragm have very different fiber type compositions during development (O'Connell et al., 2013) and into adult life (McMorrow et al., 2011); this may underlie, at least in part, differential susceptibility to $\mathrm{CIH}$ induced dysfunction. Costello et al. (2008) examined the impact of altered maternal body condition on glucose uptake in muscles of adult offspring; while fast fiber vastus muscles showed structural alterations, the slow fiber soleus muscle was reportedly unaffected and therefore may be less susceptible due to a higher proportion of type 1 myofibers (Ward and Stickland, 1991; Dwyer et al., 1994). The fast fiber sternohyoid muscle appears to show increased vulnerability to hypoxic stress compared with diaphragm and this may have implications for the control of airway caliber in vivo. The sternohyoid and diaphragm have complementary respiratory functions, but a mismatch in the force-generating capacities of the two muscles could be detrimental to the control of airway patency, since a balance of forces dictates airway caliber on a breath-by-breath basis.
Of note, we have previously reported increased susceptibility of sternohyoid compared with diaphragm in response to early life exposure to sustained hypoxia (Carberry et al., 2014).

The changes observed in sternohyoid muscle in this study may be associated with permanent alterations in gene expression orchestrated by hypoxic exposure during early life. Alterations in gene expression are regulated by graded changes in epigenetic factors such as the degree of DNA and histone methylation/acetylation and post-transcriptional and posttranslational modifications. Of note, Nanduri and Prabhakar (2013) provides evidence that increased DNA methylation induced by neonatal $\mathrm{IH}$ is implicated in neonatal programming. Genetic variation may play a role in determining subsequent sensitivity to environmental stressors such as intermittent hypoxia. These and other potential mechanisms contributing to increased vulnerability of sternohyoid muscle to hypoxic stress would be interesting areas to explore in future studies.

Our studies also suggest that younger animals display a greater capacity for hypoxia-induced muscle plasticity compared with adult animals (Carberry et al., 2014; McDonald et al., 2014, 2015b; this study). Reeves and Gozal (2006) demonstrated that the magnitude of $\mathrm{IH}$-induced respiratory plasticity is age-dependent 
TABLE 3 | Group data (mean \pm SD) for peak twitch force (Pt), contraction time (CT), half-relaxation time (HRT), optimal length (Lo), and bundle cross-sectional area (CSA) of sham and $\mathrm{CIH}$-exposed male and female sternohyoid and diaphragm muscle preparations examined under acute severe hypoxic conditions ex vivo.

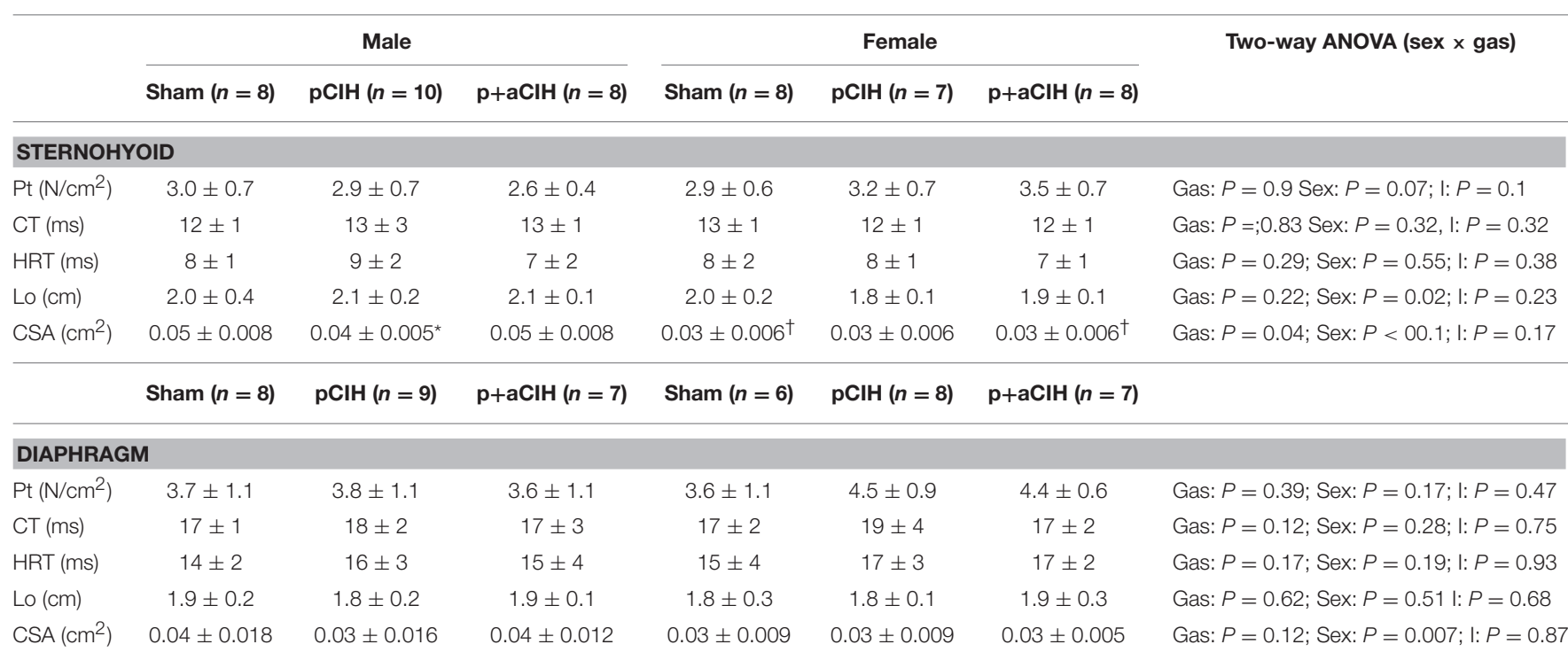

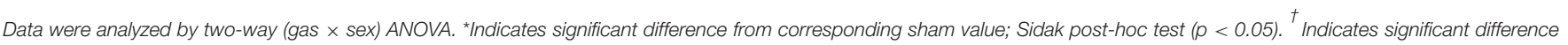
from corresponding male value; Sidak post-hoc test $(p<0.05)$.

with progressive reductions becoming apparent with advancing postnatal age. We have shown that the same $\mathrm{CIH}$ paradigm which caused force decline in neonates (that persisted for at least 3 weeks; McDonald et al., 2015b), caused little or no effect when exposures were applied in adulthood (McDonald et al., 2014) and this was confirmed by way of assessment of the effects of $\mathrm{CIH}$ on sternohyoid function in adult females in this study. Similarly, Skelly et al. (2011) reported increased tolerance to $\mathrm{CIH}$ in the sternohyoid of aged male rats compared with young adults (Skelly et al., 2012). It is also clear however that $\mathrm{CIH}$-induced maladaptation is not strictly a developmental phenomenon, since it is established that more intense paradigms of $\mathrm{CIH}$ can induce alterations in muscle physiology during adulthood. As such, Skelly et al. (2012) reported upper airway muscle dysfunction in adult rats after 9 days of $\mathrm{CIH}$ (20 cycles of $\mathrm{IH}, 5 \%$ at nadir, $8 \mathrm{~h}$ a day), a paradigm different from that used in the present study (12 cycles of $\mathrm{IH}, 5 \%$ at nadir, $8 \mathrm{~h}$ a day). Indeed it is evident that the pattern, duration, and intensity of $\mathrm{IH}$ exposure are important determinants of $\mathrm{CIH}$-induced muscle plasticity (Shortt et al., 2013). Evidence increasingly suggests that $\mathrm{CIH}$ generally has no major effect on sternohyoid, diaphragm or limb muscle fiber type expression or cross-sectional area (McGuire et al., 2002, McDonald et al., 2014, Skelly et al., 2012), though a reduction in fiber cross-section may contribute to sternohyoid weakness following pCIH (McDonald et al., 2015b). The structural phenotype of muscle is not easily altered by $\mathrm{CIH}$, which may not be surprising given the metabolic cost of structural changes. Though the molecular mechanisms underpinning functional remodeling in respiratory muscles are unclear at this time they clearly warrant further investigation as the findings may have translational value. A recent study from our group implicates altered NADPH oxidase-dependent redox signaling in adult rat sternohyoid exposed to $\mathrm{CIH}$ (Williams et al., 2015). CIH stress is insufficient to cause overt oxidation of protein and lipids in respiratory muscle (McDonald et al., 2015b, Williams et al., 2015), but the ensuing modest redox stress which weakens muscle is amenable to antioxidant supplementation (Shortt et al., 2014, Skelly et al., 2012).

In summary, this study reveals increased susceptibility to hypoxia in male and female sternohyoid muscle (but not diaphragm) in adulthood that relates to antecedent intermittent hypoxia exposure during postnatal development, revealed following re-exposure to the stressor during later life. The $\mathrm{CIH}$ stress is itself apparently innocuous in adulthood, insofar as exposure in otherwise naïve animals (i.e., reared in normoxia) does not affect sternohyoid and diaphragm muscle function. Our data may have implications for the control of airway patency in humans who are exposed to intermittent hypoxia in early life (e.g., AOP, chronic lung disease). The pharyngeal dilator muscles play a pivotal role in the control of airway caliber. Upper airway muscle dysfunction increases the risk of upper airway collapse. As such, it is tempting to speculate that if airway dilator weakness is a consequence of $\mathrm{CIH}$ exposure in humans during early development (or at any time), there may be a greater propensity for airway collapse, which could trigger an inescapable cycle perpetuating obstructive airway conditions. We acknowledge however the need for cautious extrapolation of the findings of our study in an animal model to human disorders. Our study highlights the need for additional studies exploring the long-term consequences of early life hypoxia on respiratory system performance in adult life. Of note, neonatologists remain uncertain of optimal target oxygen saturation levels in preterm infants e.g., $86-90$ or $91-95 \%$. Interventional treatment in this setting, which in the majority of circumstances is an increase 
in oxygen delivery, probably results in periods of hypoxia alternating with hyperoxia. This would be an interesting model to explore in future studies.

\section{AUTHOR CONTRIBUTIONS}

FM and KO designed the study. FM conducted experiments and analyzed data. FM and $\mathrm{KO}$ interpreted data sets and performed

\section{REFERENCES}

Bavis, R. W., Dmitrieff, E. F., Young, K. M., and Piro, S. E. (2011). Hypoxic ventilatory response of adult rats and mice after developmental hyperoxia. Respir. Physiol. Neurobiol. 177, 342-346. doi: 10.1016/j.resp.2011.05.005

Bavis, R. W., and Mitchell, G. S. (2008). Long-term effects of the perinatal environment on respiratory control. J. Appl. Physiol. 104, 1220-1229. doi: 10.1152/japplphysiol.01086.2007

Bavis, R. W., Olson, E. B. Jr., Vidruk, E. H., Fuller, D. D., and Mitchell, G. S. (2004). Developmental plasticity of the hypoxic ventilatory response in rats induced by neonatal hypoxia. J. Physiol. 557, 645-660. doi: 10.1113/jphysiol.2004.061408

Bavis, R. W., Young, K. M., Barry, K. J., Boller, M. R., Kim, E., Klein, P. M., et al. (2010). Chronic hyperoxia alters the early and late phases of the hypoxic ventilatory response in neonatal rats. J. Appl. Physiol. 109, 796-803. doi: 10.1152/japplphysiol.00510.2010

Cantillon, D., and Bradford, A. (1998). Effect of gender on rat upper airway muscle contractile properties. Respir. Physiol. 113, 147-156. doi: 10.1016/S00345687(98)00055-3

Cantillon, D., and Bradford, A. (2000). Effects of age and gender on rat upper airway muscle contractile properties. J. Gerontol. A Biol. Sci. Med. Sci. 55, B396-B400. doi: 10.1093/gerona/55.8.B396

Carberry, J. C., McMorrow, C., Bradford, A., Jones, J. F. X., and O'Halloran, K. D. (2014). Effects of sustained hypoxia on sternohyoid and diaphragm muscle during development. Eur. Respir. J. 43, 1149-1158. doi: 10.1183/09031936.00139512

Costello, P. M., Rowlerson, A., Astaman, N. A., Anthony, F. E. W., Sayer, A. A., Cooper, C., et al. (2008). Peri-implantation and late gestation maternal undernutrition differentially affect fetal sheep skeletal muscle development. J. Physiol. 586, 2371-2379. doi: 10.1113/jphysiol.2008.150987

De Boo, H. A., and Harding, J. E. (2006). The developmental origins of adult disease (Barker) hypothesis. Aust. N.Z. J. Obstet. Gynaecol. 46, 4-14. doi: 10.1111/j.1479-828X.2006.00506.x

Dick, T. E., Hsieh, Y. H., Wang, N., and Prabhakar, N. (2007). Acute intermittent hypoxia increases both phrenic and sympathetic nerve activities in the rat. Exp. Physiol. 92, 87-97. doi: 10.1113/expphysiol.2006.035758

Donnelly, D. F., Kim, I., Carle, C., and Carroll, J. L. (2005). Perinatal hyperoxia for 14 days increases nerve conduction time and the acute unitary response to hypoxia of rat carotid body chemoreceptors. J. Appl. Physiol. 99, 114-119. doi: 10.1152/japplphysiol.01009.2004

Dwyer, C., Stickland, N., and Fletcher, J. (1994). The influence of maternal nutrition on muscle fiber number development in the porcine fetus and on subsequent postnatal growth. J. Anim. Sci. 72, 911-917.

Edge, D., Bradford, A., Jones, J. F. X., and O'Halloran, K. D. (2012a). Chronic Intermittent Hypoxia Alters Genioglossus Motor Unit Characteristics in the Anaesthetised Rat. New York, NY: Springer.

Edge, D., Jones, J. F., Bradford, A., O’Halloran, K. D. (2012b). Effect of chronic intermittent hypoxia on reflex recruitment of sternohyoid EMG during airway obstruction in the anaesthetised rat. Proc. Physiol. Soc. 27:PC223.

Gale, C. R., Martyn, C. N., Kellingray, S., Eastell, R., and Cooper, C. (2001). Intrauterine programming of adult body composition. J. Clin. Endocrinol. Metab. 86, 267-272. doi: 10.1210/jc.86.1.267

Hediger, M. L., Overpeck, M. D., Kuczmarski, R. J., Mcglynn, A., Maurer, K. R., and Davis, W. W. (1998). Muscularity and fatness of infants and young children born small- or large-for-gestational-age. Pediatrics 102:e60. doi: 10.1542/peds.102.5.e60 statistical analyses. All authors contributed to the writing of the manuscript.

\section{FUNDING}

Funded by Health Research Board (Ireland). FM was funded by the School of Medicine and Medical Science, University College Dublin, Ireland.
Hibbs, A. M., Johnson, N. L., Rosen, C. L., Kirchner, H. L., Martin, R., StorferIsser, A., et al. (2008). Prenatal and neonatal risk factors for sleep disordered breathing in school-aged children born preterm. J. Pediatr. 153, 176-182. doi: 10.1016/j.jpeds.2008.01.040

Jensen, C. B., Storgaard, H., Madsbad, S., Richter, E. A., and Vaag, A. A. (2007). Altered skeletal muscle fiber composition and size precede whole-body insulin resistance in young men with low birth weight. J. Clin. Endocrinol. Metab. 92, 1530-1534. doi: 10.1210/jc.2006-2360

Julien, C., Bairam, A., and Joseph, V. (2008). Chronic intermittent hypoxia reduces ventilatory long-term facilitation and enhances apnea frequency in newborn rats. Am. J. Physiol. Regul. Integr. Comp. Physiol. 294, R1356-R1366. doi: 10.1152/ajpregu.00884.2007

Katz, S. L. (2009). Assessment of sleep-disordered breathing in pediatric neuromuscular diseases. Pediatrics 123(Suppl. 4), S222-S225. doi: 10.1542/peds.2008-2952e

Kuh, D., Bassey, J., Hardy, R., Aihie Sayer, A., Wadsworth, M., and Cooper, C. (2002). Birth weight, childhood size, and muscle strength in adult life: evidence from a birth cohort study. Am. J. Epidemiol. 156, 627-633. doi: 10.1093/aje/kwf099

Kuh, D., Hardy, R., Butterworth, S., Okell, L., Wadsworth, M., Cooper, C., et al. (2006). Developmental origins of midlife grip strength: findings from a birth cohort study. J. Gerontol. A Biol. Sci. Med. Sci. 61, 702-706. doi: 10.1093/gerona/61.7.702

Mage, D. T., and Donner, M. (2006). Female resistance to hypoxia: does it explain the sex difference in mortality rates? J. Womens. Health (Larchmt). 15, 786-794. doi: 10.1089/jwh.2006.15.786

Marshall, B. E., and Wyche, M. Q. Jr. (1972). Hypoxemia during and after anesthesia. Anesthesiology 37, 178-209. doi: 10.1097/00000542-19720800000009

Mayer, C. A., Ao, J., Di Fiore, J. M., Martin, R. J., and Macfarlane, P. M. (2013). Impaired hypoxic ventilatory response following neonatal sustained and subsequent chronic intermittent hypoxia in rats. Respir. Physiol. Neurobiol. 187, 167-175. doi: 10.1016/j.resp.2013.03.011

McDonald, F. B., Edge, D., and O'Halloran, K. D. (2014). Chapter 12 Chronic nitric oxide synthase inhibition does not impair upper airway muscle adaptation to chronic intermittent hypoxia in the rat. Prog. Brain Res. 212, 237-251. doi: 10.1016/B978-0-444-63488-7.00012-4

McDonald, F. B., Skelly, J. R., and O'Halloran, K. D. (2015a). The ß2adrenoceptor agonist terbutaline recovers rat pharyngeal dilator muscle force decline during severe hypoxia. Oral Dis. 21, e121-e127. doi: 10.1111/odi. 12247

McDonald, F. B., Williams, R., Sheehan, D., and O'Halloran, K. D. (2015b). Early life exposure to chronic intermittent hypoxia causes upper airway dilator muscle weakness, which persists into young adulthood. Exp. Physiol. 100, 947-966. doi: 10.1113/EP085003

McGuire, M., Macdermott, M., and Bradford, A. (2002). The effects of chronic episodic hypercapnic hypoxia on rat upper airway muscle contractile properties and fiber-type distribution. Chest 122, 1400-1406. doi: $10.1378 /$ chest.122.4.1400

McMorrow, C., Fredsted, A., Carberry, J., O’Connell, R. A., Bradford, A., Jones, J. F. X., et al. (2011). Chronic hypoxia increases rat diaphragm muscle endurance and Na+-K+ ATPase pump content. Eur. Respir. J. 37, 1474-1481. doi: $10.1183 / 09031936.00079810$

McNamara, F., and Sullivan, C. E. (2000). The genesis of adult sleep apnoea in childhood. Thorax 55, 964-969. doi: 10.1136/thorax.55.11.964 
Moss, I. R., and Laferrière, A. (2006). Long term recurrent hypoxia in developing rat attenuates respiratory responses to subsequent acute hypoxia: proposed mechanisms. FASEB J. 20:A1211. doi: 10.1203/01.pdr.0000203104.45807.23

Nanduri, J., and Prabhakar, N. R. (2013). Developmental programming of O2 sensing by neonatal intermittent hypoxia via epigenetic mechanisms. Respir. Physiol. Neurobiol. 185, 105-109. doi: 10.1016/j.resp.2012.07.016

O'Connell, R. A., Carberry, J., and O'Halloran, K. D. (2013). Sternohyoid and diaphragm muscle form and function during postnatal development in the rat. Exp. Physiol. 98, 1386-1400. doi: 10.1113/expphysiol.2013.073346

O'Halloran, K. D. (2006). Effects of nicotine on rat sternohyoid muscle contractile properties. Respir. Physiol. Neurobiol. 150, 200-210. doi: 10.1016/j.resp.2005.05.018

O'Halloran, K. D., McGuire, M., O'hare, T., and Bradford, A. (2002). Chronic intermittent asphyxia impairs rat upper airway muscle responses to acute hypoxia and asphyxia. Chest 122, 269-275. doi: 10.1378/chest.122.1.269

Pae, E.-K., Wu, J., Nguyen, D., Monti, R., and Harper, R. M. (2005). Geniohyoid muscle properties and myosin heavy chain composition are altered after short-term intermittent hypoxic exposure. J. Appl. Physiol. 98, 889-894. doi: 10.1152/japplphysiol.00978.2004

Pawar, D. (2012). Common post-operative complications in children. Indian J. Anaesth. 56, 496-501. doi: 10.4103/0019-5049.103970

Peng, Y. J., Overholt, J. L., Kline, D., Kumar, G. K., and Prabhakar, N. R. (2003). Induction of sensory long-term facilitation in the carotid body by intermittent hypoxia: implications for recurrent apneas. Proc. Natl. Acad. Sci. U.S.A. 100, 10073-10078. doi: 10.1073/pnas.1734109100

Peng, Y.-J., Rennison, J., and Prabhakar, N. R. (2004). Intermittent hypoxia augments carotid body and ventilatory response to hypoxia in neonatal rat pups. J. Appl. Physiol. 97, 2020-2025. doi: 10.1152/japplphysiol.00876.2003

Phillips, D. I. W. (1995). Relation of fetal growth to adult muscle mass and glucose tolerance. Diabet. Med. 12, 686-690. doi: 10.1111/j.1464-5491.1995.tb00570.x

Prabhakar, N. R., Peng, Y.-J., Kumar, G. K., and Pawar, A. (2007). Altered carotid body function by intermittent hypoxia in neonates and adults: relevance to recurrent apneas. Respir. Physiol. Neurobiol. 157, 148-153. doi: 10.1016/j.resp.2006.12.009

Raynes-Greenow, C. H., Hadfield, R. M., Cistulli, P. A., Bowen, J., Allen, H., and Roberts, C. L. (2012). Sleep apnea in early childhood associated with preterm birth but not small for gestational age: a population-based record linkage study. Sleep 35, 1475-1480. doi: 10.5665/sleep.2192

Reeves, S. R., and Gozal, D. (2006). Changes in ventilatory adaptations associated with long-term intermittent hypoxia across the age spectrum in the rat. Respir. Physiol. Neurobiol. 150, 135-143. doi: 10.1016/j.resp.2005.03.018

Reeves, S. R., Mitchell, G. S., and Gozal, D. (2006). Early postnatal chronic intermittent hypoxia modifies hypoxic respiratory responses and long-term phrenic facilitation in adult rats. Am. J. Physiol. Regul. Integr. Comp. Physiol. 290, R1664-R1671. doi: 10.1152/ajpregu.00851.2005

Roberts, J. L., Reed, W. R., and Thach, B. T. (1984). Pharyngeal airway-stabilizing function of sternohyoid and sternothyroid muscles in the rabbit. J. Appl. Physiol. Respir. Environ. Exerc. Physiol. 57, 1790-1795.

Rosen, C. L., Larkin, E. K., Kirchner, H. L., Emancipator, J. L., Bivins, S. F., Surovec, S. A., et al. (2003). Prevalence and risk factors for sleep-disordered breathing in 8- to 11-year-old children: association with race and prematurity. J. Pediatr. 142, 383-389. doi: 10.1067/mpd.2003.28

Sayer, A. A., Cooper, C., Evans, J. R., Rauf, A., Wormald, R. P., Osmond, C., et al. (1998). Are rates of ageing determined in utero? Age Ageing 27, 579-583.

Sayer, A. A., Syddall, H. E., Dennison, E. M., Gilbody, H. J., Duggleby, S. L., Cooper, C., et al. (2004). Birth weight, weight at $1 \mathrm{y}$ of age, and body composition in older men: findings from the Hertfordshire Cohort Study. Am. J. Clin. Nutr. 80, 199-203.
Shortt, C. M., Fredsted, A., Bradford, A., and O'Halloran, K. D. (2013). Diaphragm muscle remodelling in a rat model of chronic intermittent hypoxia. J. Histochem. Cytochem. 61, 487-499. doi: 10.1369/0022155413490947

Shortt, C. M., Fredsted, A., Chow, H. B., Williams, R., Skelly, J. R., Edge, D., et al. (2014). Reactive oxygen species mediated diaphragm fatigue in a rat model of chronic intermittent hypoxia. Exp. Physiol. 99, 688-700. doi: 10.1113/expphysiol.2013.076828

Skelly, J. R., Edge, D., Shortt, C. M., Jones, J. F. X., Bradford, A., and O'Halloran, K. D. (2012). Tempol ameliorates pharyngeal dilator muscle dysfunction in a rodent model of chronic intermittent hypoxia. Am. J. Respir. Cell Mol. Biol. 46, 139-148. doi: 10.1165/rcmb.2011-0084OC

Skelly, J. R., O'Connell, R. A., Jones, J. F., and O'Halloran, K. D. (2011). Structural and functional properties of an upper airway dilator muscle in aged obese male rats. Respiration 82, 539-549. doi: 10.1159/000332348

Soukhova-O'hare, G. K., Cheng, Z. J., Roberts, A. M., and Gozal, D. (2006). Postnatal intermittent hypoxia alters baroreflex function in adult rats. Am. J. Physiol. Heart Circ. Physiol. 290, H1157-H1164. doi: 10.1152/ajpheart.00767.2005

Strohl, K. P., Wolin, A. D., Van Lunteren, E., and Fouke, J. M. (1987). Assessment of muscle action on upper airway stability in anesthetized dogs. J. Lab. Clin. Med. 110, 221-230.

Thach, B. T. (1985). Sleep apnea in infancy and childhood. Med. Clin. North Am. 69, 1289-1315.

Van De Graaff, W. B., Gottfried, S. B., Mitra, J., Van Lunteren, E., Cherniack, N. S., and Strohl, K. P. (1984). Respiratory function of hyoid muscles and hyoid arch. J. Appl. Physiol. 57, 197-204.

Van Lunteren, E., Haxhiu, M. A., and Cherniack, N. S. (1987a). Mechanical function of hyoid muscles during spontaneous breathing in cats. J. Appl. Physiol. 62, 582-590.

Van Lunteren, E., Haxhiu, M. A., and Cherniack, N. S. (1987b). Relation between upper airway volume and hyoid muscle length. J. Appl. Physiol. 63, 1443-1449.

Van Lunteren, E., Haxhiu, M. A., and Cherniack, N. S. (1989). Effects of tracheal airway occlusion on hyoid muscle length and upper airway volume. J. Appl. Physiol. 67, 2296-2302.

Vuono, I. M., Zanoteli, E., De Oliveira, A. S., Fujita, R. R., Pignatari, S. S., Pizarro, G. U., et al. (2007). Histological analysis of palatopharyngeal muscle from children with snoring and obstructive sleep apnea syndrome. Int. J. Pediatr. Otorhinolaryngol. 71, 283-290. doi: 10.1016/j.ijporl.2006.10.019

Ward, S., and Stickland, N. (1991). Why are slow and fast muscles differentially affected during prenatal undernutrition? Muscle Nerve 14, 259-267.

Williams, R., Lemaire, P., Lewis, P., McDonald, F. B., Lucking, E., Hogan, S., et al. (2015). Chronic intermittent hypoxia increases rat sternohyoid muscle NADPH oxidase expression with attendant modest oxidative stress. Front. Physiol. 6:15. doi: 10.3389/fphys.2015.00015

Yliharsila, H., Kajantie, E., Osmond, C., Forsen, T., Barker, D. J. P., and Eriksson, J. G. (2007). Birth size, adult body composition and muscle strength in later life. Int. J. Obes. 31, 1392-1399. doi: 10.1038/sj.ijo.0803612

Conflict of Interest Statement: The authors declare that the research was conducted in the absence of any commercial or financial relationships that could be construed as a potential conflict of interest.

Copyright $\odot 2016$ McDonald, Dempsey and O'Halloran. This is an open-access article distributed under the terms of the Creative Commons Attribution License (CC $B Y)$. The use, distribution or reproduction in other forums is permitted, provided the original author(s) or licensor are credited and that the original publication in this journal is cited, in accordance with accepted academic practice. No use, distribution or reproduction is permitted which does not comply with these terms. 